\title{
Dayside aurorae and polar arcs under south-east IMF orientation
}

\author{
P. E. Sandholt ${ }^{1}$, M. Dyrland ${ }^{2}$, and C. J. Farrugia ${ }^{3}$ \\ ${ }^{1}$ Department of Physics, University of Oslo, Oslo, Norway \\ ${ }^{2}$ The University Centre in Svalbard, Longyearbyen, Norway \\ ${ }^{3}$ Space Science Center, University of New Hampshire, Durham, USA
}

Received: 12 June 2006 - Revised: 26 October 2006 - Accepted: 2 November 2006 - Published: 21 December 2006

\begin{abstract}
We document a characteristic spatial and temporal structure of the aurora in the postnoon sector present during a 10-h-long interval of very steady southeast IMF orientation (clock angle $=135^{\circ}$ ) ending in a sharp south-to-north transition. Focus is placed on the detailed morphology of auroral forms/activities corresponding to merging and lobe convection cells obtained from SuperDARN convection data and Greenland magnetograms. The ground optical instruments at Ny Ålesund, Svalbard (76 ${ }^{\circ}$ MLAT) recorded different auroral forms/activities as the station moved to higher magnetic local times (MLTs) in the 13:00-17:00 MLT sector. Whereas the 13:00-15:00 MLT sector is characterized by classical poleward moving auroral forms (PMAFs) associated with merging cell transients, the aurora in the 15:0017:00 MLT sector shows instead a characteristic latitudinal bifurcation consisting of standard oval forms and polar arcs, and a corresponding composite pattern of merging and lobe convection cells. The merging and lobe cells respond to the southward and northward IMF transitions by activation/fading and fading/activation, respectively. A sequence of brightening events is characterized by successive activations progressing in latitude from the merging cell regime to the lobe cell regime. Emphasis is placed on the association between polar arc brightenings and the activation of the channel of enhanced sunward flow in the lobe cell. The observations are discussed in relation to recent work on solar wind-magnetosphere-ionosphere interconnection topology.
\end{abstract}

Keywords. Magnetospheric physics (Auroral phenomena; Magnetopause, cusp and boundary layers; Solar windmagnetosphere interactions)

\section{Introduction}

The question of the spatial and temporal structure of the cusp/cleft ionosphere and its relationship to solar windmagnetosphere interconnection topology have been and still

Correspondence to: P. E. Sandholt

(p.e.sandholt@fys.uio.no) are great challenges to the magnetospheric physics community. One of the factors that contribute to the complexity of the problem is the variability of external conditions in the solar wind. To mitigate the problem of separating the spatial and temporal structure we have searched for long intervals of "steady" IMF and solar wind conditions. Under such conditions one can expect rather stable particle precipitation boundaries. One can use continuous auroral observations from a single ground station to delineate spatial structure in the precipitation pattern as the station sweeps through different sectors of magnetic local time (MLT). In a recent study this technique has been used to reveal interesting spatial structure within in the 09:00-14:00 MLT sector during southeast directed IMF (Sandholt et al., 2004).

An outstanding spatial structure in the dayside aurora appearing during intervals with IMF $B_{z}<0$ and non-zero IMF $B_{y}$ component is the presence of a longitudinally restricted band of strongly attenuated auroral emission, a so-called "midday gap aurora", surrounded by auroral brightenings on both sides. The "midday gap aurora" is characterized by the absence $(<1 \mathrm{kR})$ of green line emission, and attenuated red line intensity, particularly during $B_{y}>0$ conditions (Dandekar and Pike, 1978; Sandholt et al., 2004). The brightening events in the pre- and postnoon sectors are followed by poleward moving auroral forms (PMAFs). The latter aurora is considered to be a signature of flux transfer events (FTEs) (Sandholt et al., 1990; Fasel, 1995). The auroral feature mentioned above is an example of a precipitation structure that can appear within the field of view of one single ground optical instrument, due to the fact that widely separated magnetopause plasma sources may map to rather closely spaced locations in the ionosphere (Sandholt et al., 1998; Maynard et al., 2001; Sandholt et al., 2004). The auroral observation has important implications for magnetopause reconnection topology. It is consistent with the recent MHD simulation results of Park et al. (2006) in that the most geo-effective magnetopause reconnection process under the given IMF condition occurs where the magnetic fields are near anti-parallel in the pre- and postnoon sectors, well away from the subsolar point. Thus from the auroral observations

Published by Copernicus GmbH on behalf of the European Geosciences Union. 
showing the presence of three different auroral features in three different MLT sectors (PMAFs/prenoon, "midday gap aurora", PMAFs/postnoon) we may learn that different reconnection modes are simultaneously in operation during a southeast (or southwest) IMF. First, there is an intermittent type activity (FTEs) corresponding to the auroral brightening events/PMAFs. Second, there is a quasi-steady reconnection mode originating in the subsolar region and corresponding to the more stable auroral arc ("midday gap aurora") stretching across noon. The implication is that the subsolar reconnection is of the component-type, since in the subsolar region the geomagnetic field and the IMF with a nonzero $B_{y}$ component are not anti-parallel (Moore et al., 2002).

In this paper we shall apply the technique of continuous ground observations during quasi-steady external conditions for monitoring spatial magnetospheric structure in the postnoon (14:00-17:00 MLT) sector during an interval of southeast IMF orientation (clock angle $\sim 135^{\circ}$ ). We shall in particular be concerned with the structure in aurora/precipitation which is associated with a composite pattern of merging and lobe convection cells. According to large statistical studies of convection data, the lobe cell under the given IMF conditions is most strongly manifest in the summer season (Weimer, 1995). Since our case (12 December) is close to winter solstice the question of the presence of a lobe cell in the northern hemisphere is an interesting issue. We shall place the focus on the auroral signature.

Before returning to the lobe cell auroral activity, we comment on the merging cell aurora under nonzero $B_{y}$ conditions, which is dominated by the brightening events and PMAFs mentioned above. In the dusk cell each event is observed to expand westward (noonward) and poleward in the 12:00-14:00 MLT sector (Sandholt et al., 1990, 1998; Milan et al., 2000; Sandholt and Farrugia, 2003). This auroral activity and motion is confirmed in the present case. It may be explained by transient events of antiparallel reconnection occurring at high magnetopause latitudes in the postnoon sector (Maynard et al., 2001, 2003; Sandholt and Farrugia, 2003). In a recent study we pointed out the presence of an interesting contrast between PMAFs in the prenoon and those appearing in the postnoon sector (Sandholt and Farrugia, 2006b). While the PMAFs/prenoon develop in three stages (latitudinally separate forms) spanning a latitude range of $\geq 500 \mathrm{~km}$, the highest-latitude stage is absent in PMAFs/postnoon for $B_{y}>0$, which after the initial intensification, progressively fade. The precipitation asymmetry about noon in the PMAF activity is found to be associated with the dusk-dawn convection asymmetry and the solar wind-magnetosphere interconnection topology induced by IMF $B_{y}$.

The lobe cell is generally thought to be a northward IMF phenomenon. In such cases the requirement of near antiparallel IMF and lobe field is easily fulfilled in magnetopause regions poleward of the cusp (Crooker, 1979). However, according to the MHD simulation study of Crooker et al.
(1998), the lobe cell may not disappear when the IMF $B_{z}$ component goes negative as long as a substantial $B_{y}$ component is present (see also Reiff and Burch, 1985). When $B_{y}$ is large in comparison to $B_{z}$, the lobe cell is thought to exist regardless of the $B_{z}$ polarity. This result has been confirmed by observations from the FAST satellite reported by Eriksson et al. $(2002,2003)$ and from DMSP F13 data during interplanetary magnetic cloud conditions reported by Sandholt and Farrugia (2006a). They find that a lobe cell is generally present when $\left|B_{y} / B_{z}\right| \geq 1$. We note that their examples are mainly from the summer and spring (March-April) seasons so none suffered from a seasonal disadvantage. By contrast we address here the winter season.

In a previous case study of the aurora under similar IMF conditions $\left(\theta=135^{\circ} ; B_{y}\right.$ positive) we claimed to see auroral and convection signatures of a lobe cell (Sandholt et al., 2003). However, since in that case the optical and ion drift coverage in the postnoon sector was limited, the interpretation was not unambiguous. It was not a trivial task to distinguish between auroral activities related to the lobe and merging cells in that case. This limitation also applies to the study of Sandholt et al. (2001).

In the present case we have very good optical coverage in the whole postnoon/dusk sector so this is a good opportunity to document the appearance of lobe cell signatures. A dramatic change in the auroral structure was observed from the ground site at 11:20 UT/15:00 MLT under steady IMF conditions. From mid-afternoon to dusk local times (15:00 17:00 MLT) the aurora configured in two latitudinally separate branches, which we shall attribute to the presence of merging and lobe convection cells. This interpretation is then supported by plasma convection data obtained by SuperDARN radars. Our interpretation is strengthened further by the response of aurora/convection to the two distinct southward and northward/eastward rotations of the IMF in the period we study (recorded by Wind at 12:00 and 12:30 UT, respectively).

In the present paper we shall therefore be able to document for the first time the detailed dynamics of the aurora and plasma convection in a composite pattern consisting of merging and lobe cells under the stated IMF conditions. This observation is discussed in the context of recent work on solar wind-magnetosphere-ionosphere interconnection topology.

\section{Data presentation}

\subsection{IMF and solar wind plasma data}

Figure 1 shows solar wind plasma and IMF observations obtained from spacecraft Wind during the interval 08:00 14:00 UT on 12 December 1999. Wind was beyond the dawn terminator at $12: 00 \mathrm{UT}(-13.8 ;-57.3 ; 15.8) R_{E}$. A steady $5 \mathrm{nT}$ IMF pointing south-east (average $B_{z}=-3 \mathrm{nT} ; B_{y}=3 \mathrm{nT}$; clock angle $\left.=135^{\circ}\right)$ is embedded in a slow $(375 \mathrm{~km} / \mathrm{s})$ and 


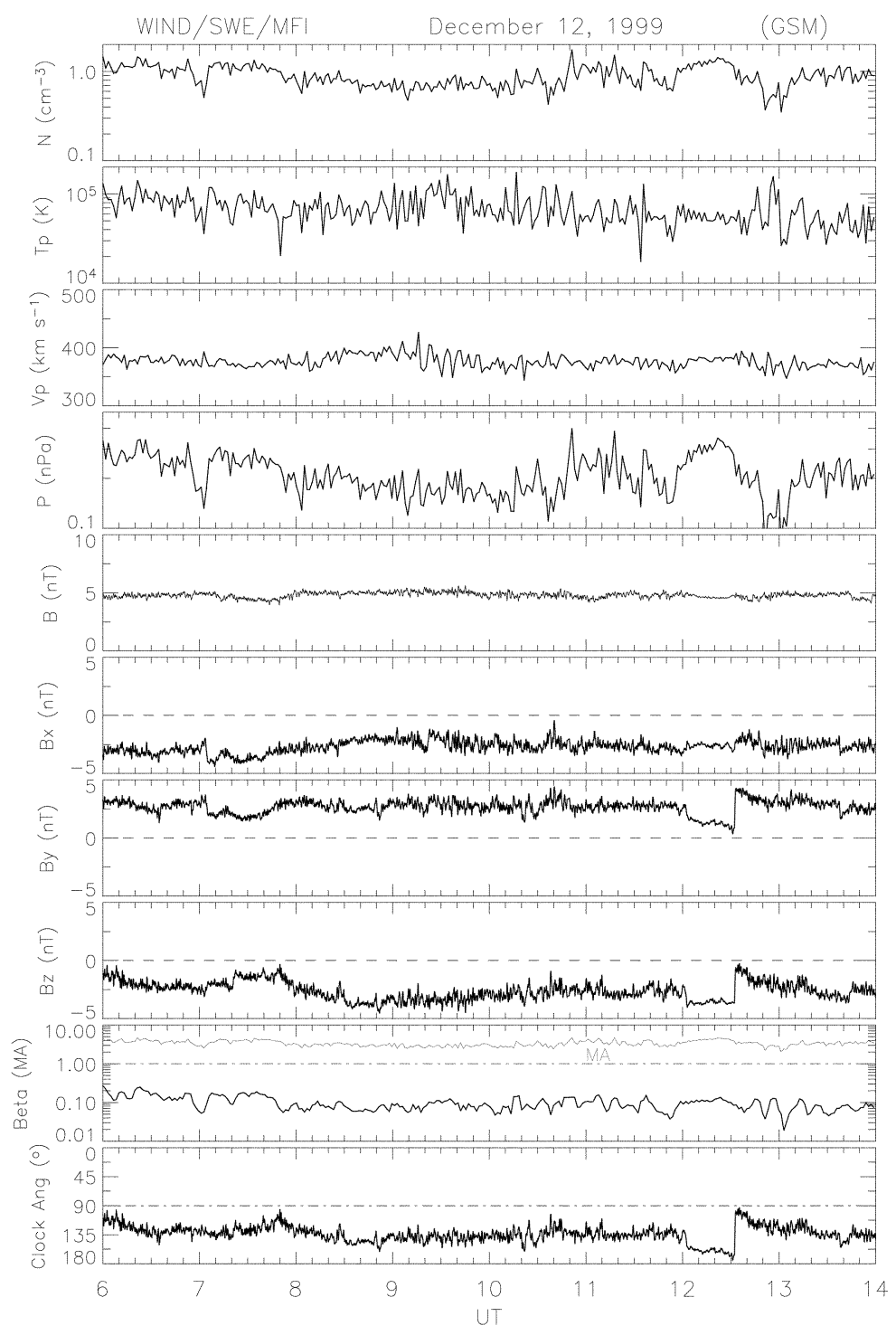

Fig. 1. Solar wind plasma and IMF observations from spacecraft Wind during the interval 06:00-14:00 UT on 12 December 1999. Panels from top to bottom shows proton density, temperature, bulk speed, solar wind dynamic pressure, the total field intensity and the GSM components $\left(B_{x}, B_{y}\right.$, and $\left.B_{z}\right)$ of the interplanetary magnetic field (IMF), Alfven-Mach number (MA), proton beta, and the clock angle in the GSM Y-Z plane.

low-density $\left(1 \mathrm{~cm}^{-3}\right)$ solar wind. The only rapid changes in the IMF during the whole interval are the southward turning at 12:00 UT and the subsequent transition to an approximately eastward orientation at 12:30 UT (clock angle change from 160 to $100^{\circ}$ ). The latter change elicited a clear response in the high latitude (75-80 $80^{\circ}$ MLAT) records from the Greenland east chain of magnetometers at 12:30 UT (see below). The negligible propagation delay between Wind and ground is consistent with Wind's position.

\subsection{Case overview}

On an MLAT-MLT grid, Fig. 2 shows a schematic summary of auroral forms for IMF $B_{y}>0$ and $B_{z}<0$ (clock angle range 90-135 ${ }^{\circ}$ ) conditions. FC 1-4 denote convection channels and their relationships with FAC systems are indicated. Particle precipitation (CPS-BPS-LL-MA) and field-aligned current (FAC; C1-C2-R1-R2) data obtained from spacecraft DMSP F7 (Sandholt and Newell, 1992) and Polar (Farrugia et al., 2003), respectively, under similar IMF conditions (south-east 


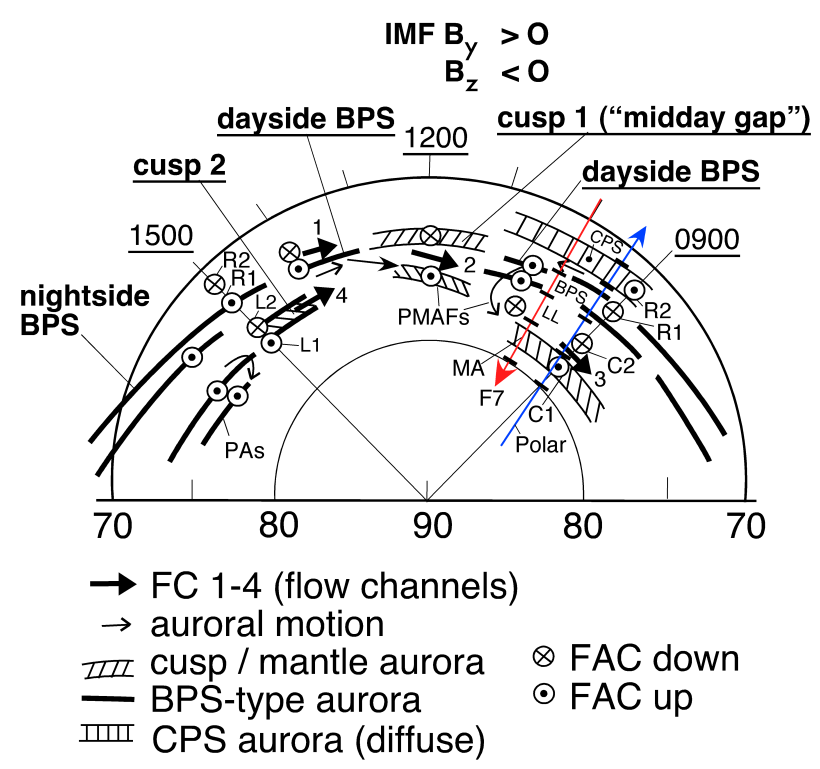

Fig. 2. Schematic illustration of auroral observations in relation to plasma convection channels on 12 December 1999. Cusp-type (LLBL, cusp and mantle) auroras are marked by hatched areas while the BPS-type forms are indicated by lines. Four different flow channels (labeled FC 1-4) and the associated field-aligned current (FAC) structure have been marked. The coordinate system is MLAT/MLT. Tracks of spacecraft Polar along 09:00 MLT and DMSP F7 along 10:00 MLT used to derive the precipitation/FAC information for other similar cases have been marked. Polar arcs (PAs) on the dusk side of the polar cap are shown.

orientation), have been incorporated in the figure (and the traces of the spacecraft trajectories shown by red and blue arrowed lines). The indicated precipitation regimes inferred from the F7 pass are central plasma sheet (CPS), boundary plasma sheet (BPS), low-latitude boundary layer (LL) and mantle (MA).

The relationship between FACs and plasma convection is of the type suggested by Southwood (1987). Region 1 (R 1) and 2 (R 2) FACs as well as the cusp currents C1-C2 and the lobe currents L1-L2 have been marked. This schematic summary figure, with emphasis on the postnoon sector, will be used as a reference for the interpretation of the aurora- and plasma convection observations presented below. A detailed discussion of the prenoon sector activity has been given by Sandholt and Farrugia (2006b).

\subsection{Auroral observations}

In order to place the postnoon sector aurora in the proper context we show in Fig. 3 meridian scanning photometer (MSP) records for an MLT range extending fron morning to evening on 12 December 1999. Magnetic noon (12:00 MLT) corresponds to $08: 30$ UT. We draw attention to the following features:

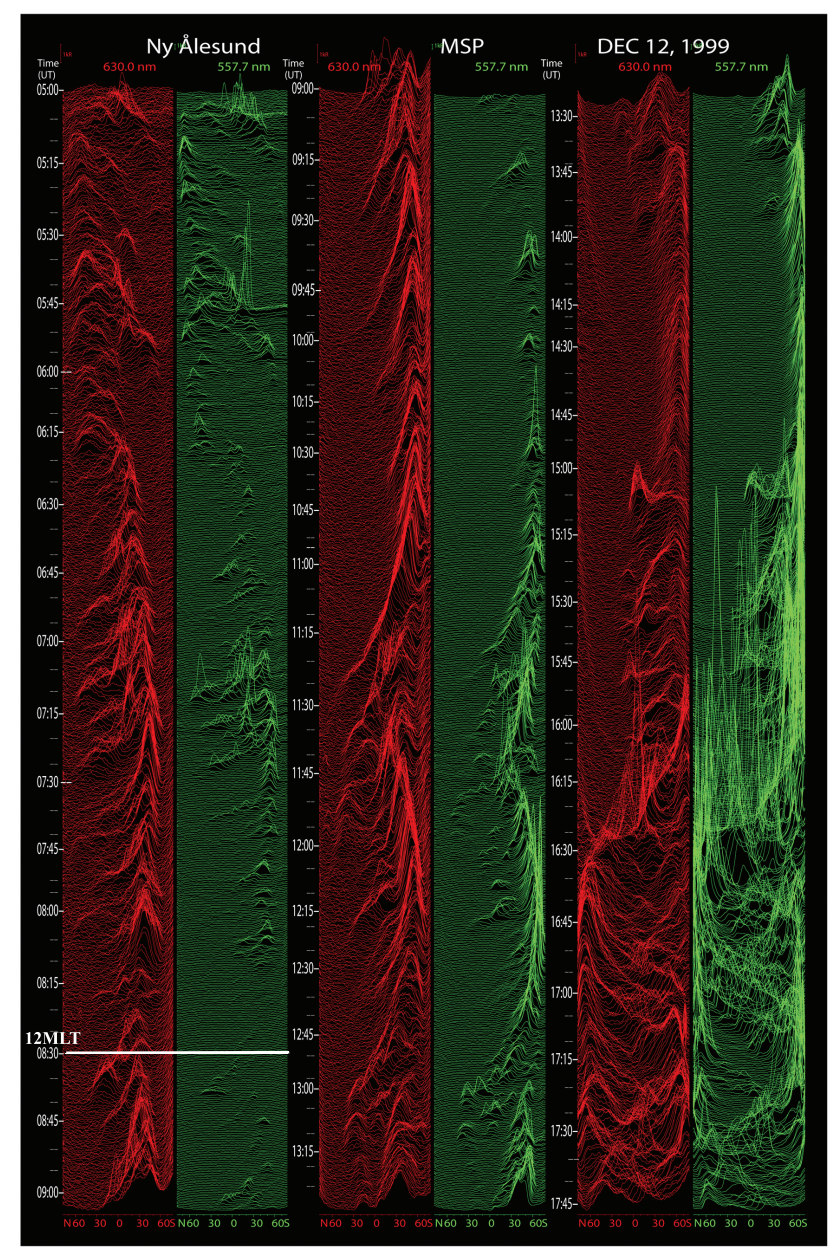

Fig. 3. MSP data obtained from Ny Ålesund for the whole day (05:00-17:45 UT; 08:30-21:15 MLT). Line-of-sight intensities are shown as a function of zenith angle for the wavelength channels at 630.0 (red) and $557.7 \mathrm{~nm}$ (green). North is to the left in each panel. Magnetic noon $(12: 00 \mathrm{MLT})=08: 30 \mathrm{UT}$.

(i) 05:00-06:00 UT (08:30-09:30 MLT): high-latitude brightening events and lower-latitude BPS arcs,

(ii) 06:30-08:15 UT (10:00-11:45 MLT): prenoon sector PMAFs,

(iii) 08:30-10:30 UT (12:00-14:00 MLT): postnoon sector PMAFs and inter-event "midday gap aurora",

(iv) 11:20-13:10 UT (14:50-16:40 MLT): oval arc in the south and polar arcs further north,

(v) 13:40-15:00 UT (17:10-18:30 MLT): homogeneous oval arc in the south,

(vi) 15:00-16:15 UT (18:30-19:45 MLT): poleward boundary intensifications (PBIs), and

(vii) 16:15 UT (19:45 MLT) onwards: major substorms characterized by (a) double-branch aurora, (b) poleward expansions, (d) PBIs, and (e) auroral streamers travelling equatorwards from the high-latitude branch to the lower-latitude branch (Sandholt and Farrugia, 2001; Sandholt et al., 2002a). 

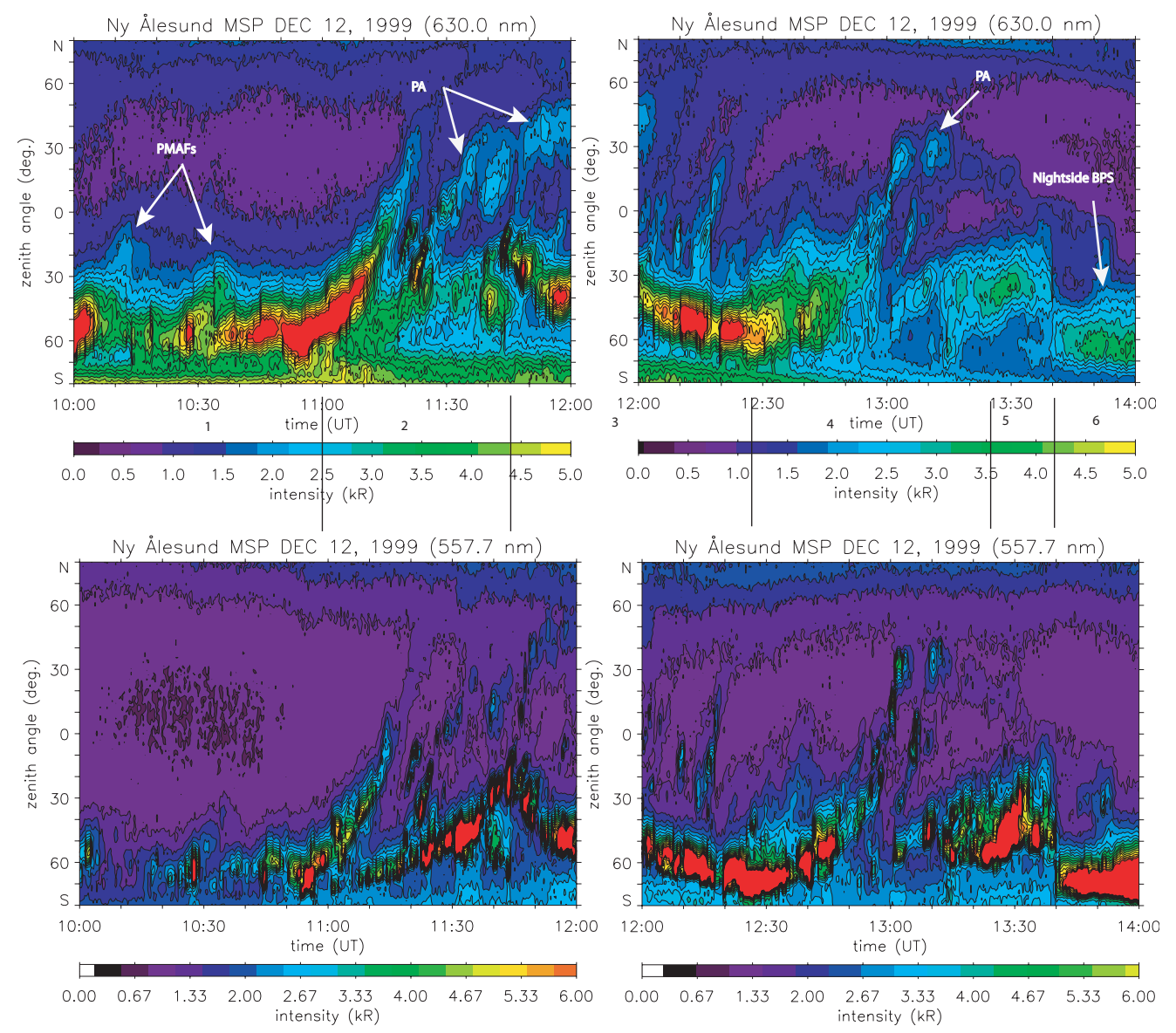

Fig. 4. MSP data for the interval 10:00-14:00 UT (13:30-17:30 MLT). Line-of-sight intensities versus zenith angle for the 630.0 and 557.7 $\mathrm{nm}$ emissions are represented by a color coded contour plot. PMAFs and polar arcs (PAs) are marked. The intensity scale is given at the bottom of each panel. North is up.

After this brief presentation of gross features of the aurora for the whole day we shall next focus on the aurora in the postnoon-dusk sector (10:30-13:20 UT/14:00-17:00 MLT), which is the main topic of this paper.

Figure 4 shows the MSP data for the interval 10:0014:00 UT (13:30-17:30 MLT) in a color-coded contour plot. The fine-structure is most easily seen in the green line panel. We shall place focus on the following features: (i) 10:00-10:30 UT: two classical brightening events followed by PMAFs, (ii) 11:10-12:00 UT: the presence of two latitudinally separate auroral branches, (iii) 12:00-12:30 UT: intense lower-latitude branch (llb) moving equatorward, higher-latitude branch (hlb) mostly absent, (iv) 12:3013:10 UT: weak llb while hlb is clearly present in the form of brightening events, (v) brightening events propagating from lower to higher latitudes, affecting both auroral branches, are observed during the following intervals: (a) 10:55-11:12 UT, (b) 11:18-11:30 UT, (c) 11:40-11:55 UT, (d) 12:10-12:20 UT, and (e) 12:40-13:00 UT. Features (iii) and (iv) occur when the IMF points strongly south $\left(\theta \sim 160^{\circ}\right)$ and almost east $\left(\theta=100-120^{\circ}\right)$, respectively.
We now document the 2-D aspects of the auroral activity by all-sky camera (ASC) images. Figure 5 shows a sequence of ASC images (interval 11:20-11:30 UT) which is representative of the auroral activity observed in the interval 11:0012:00 UT. The light integration time is $2 \mathrm{~s}$ for the $630.0 \mathrm{~nm}$ images. The central meridian at 11:30 UT corresponds to 15:00 MLT. Four intense forms are seen in the present ASC images, one to the left (west of the 15:00 MLT meridian) and three forms extending to the right (eastern) side in these pictures. We identify the northernmost forms on the eastern (dusk) side as the polar arcs (marked PA in Fig. 2). The strong form (high red line intensity) on the western boundary of the FOV is identified as a cusp form (also marked in Fig. 2) which in this case is intense at $\sim 14: 00$ MLT.

The image sequence shown in Fig. 5 illustrates the dynamics of polar arcs. The evolution of the events is characterized by a phase motion consisting of (i) the activation phase (intensification and westward expansion), which is followed by (ii) the fading phase (fading and eastward retraction). At a certain time the aurora typically configures as 2-3 fragmented arcs being in different phases of evolution. 


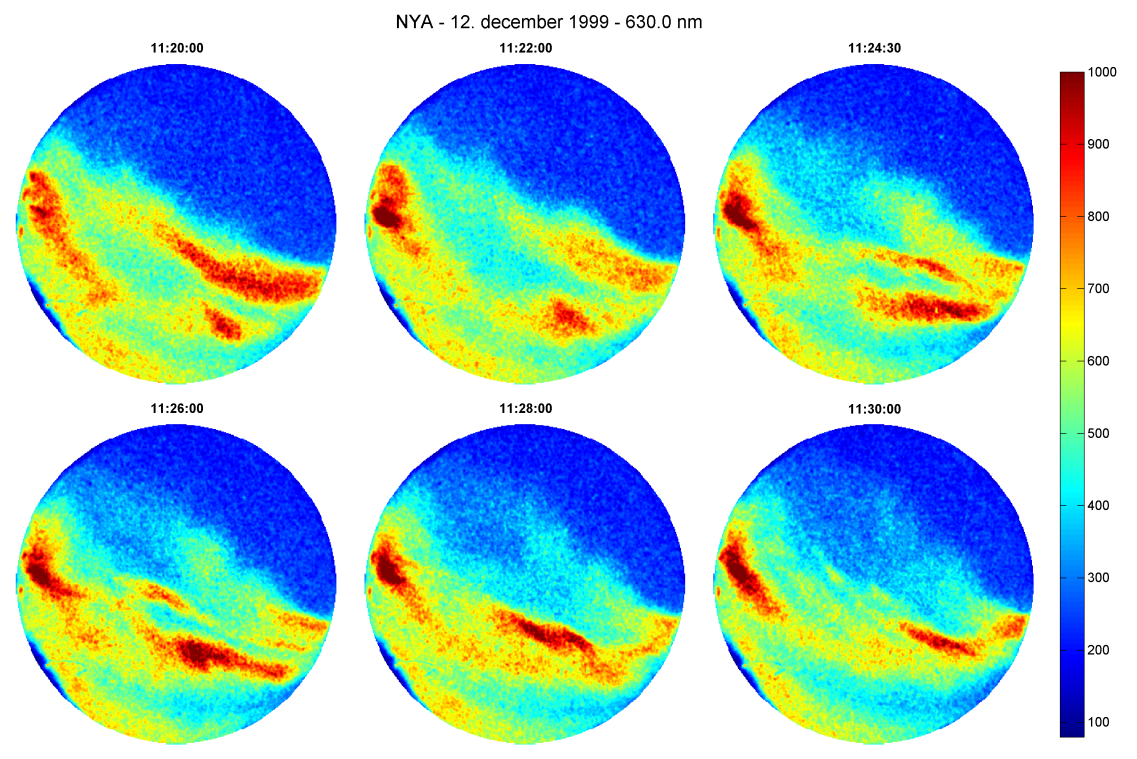

Fig. 5. ASC data representation of the $630.0 \mathrm{~nm}$ emission for the interval 11:20-11:30 UT. The coordinate system is zenith angle versus azimuth angle. Magnetic north is up. West is to the left.
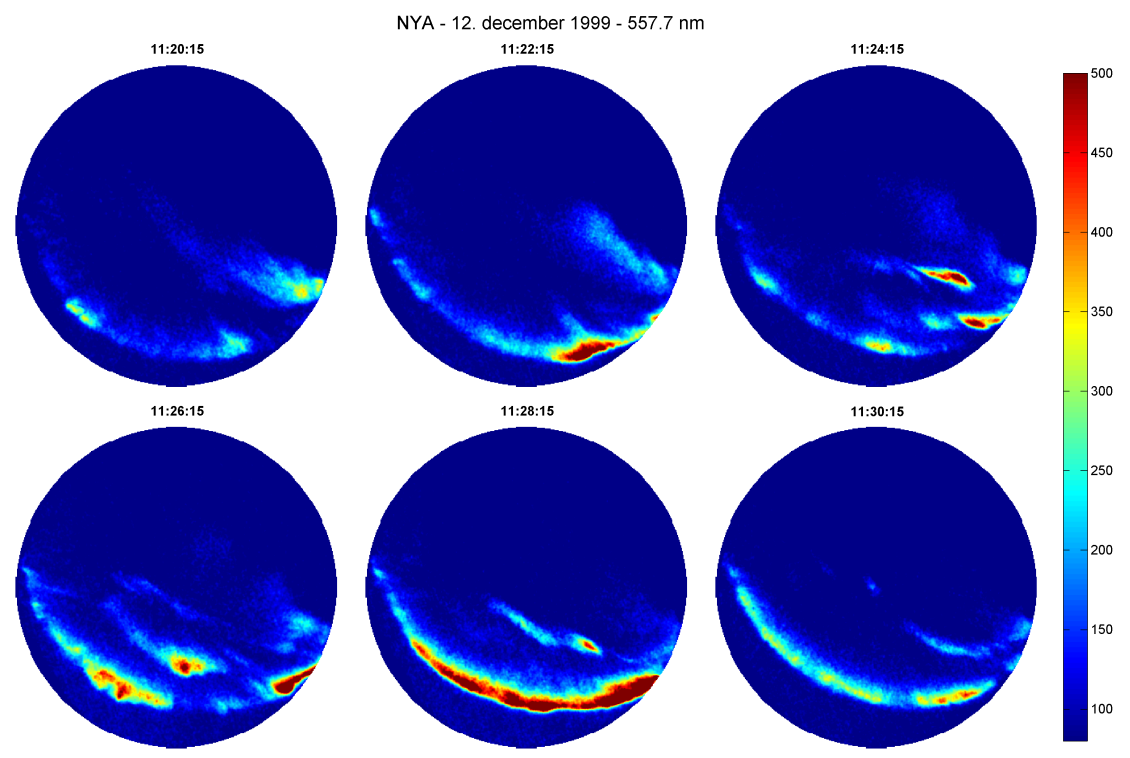

Fig. 6. ASC representation of the 557.7 nm emission for the interval 11:20-11:30 UT. Same format as in Fig. 5.

For example, at 11:24-11:26 UT the northernmost form is fading/retracting while a lower latitude form is in the brightening/expanding phase. These various phases are marked by the curled arrow attached to the arcs in Fig. 2.

Figure 6 shows the $557.7 \mathrm{~nm}$ counterpart to Fig. 5. The light integration time for the $557.7 \mathrm{~nm}$ images is $1 \mathrm{~s}$. The southernmost arc is a rather homogeneous precipitation which we identify as the nightside BPS arc marked in Fig. 2. This arc intensifies at 11:28 UT (middle image in lower panel). The arcs to the north of this are seen to expand into the FOV from the eastern (right) side, followed by poleward and eastward retraction, as described above. We note that the cusp arc at the western boundary, which is strongly present in the red line emission, does not appear in the green line emission. This is consistent with the lower characteristic energy $(<300 \mathrm{eV})$ of the electrons exciting this cusp-type aurora (Newell and Meng, 1988). 

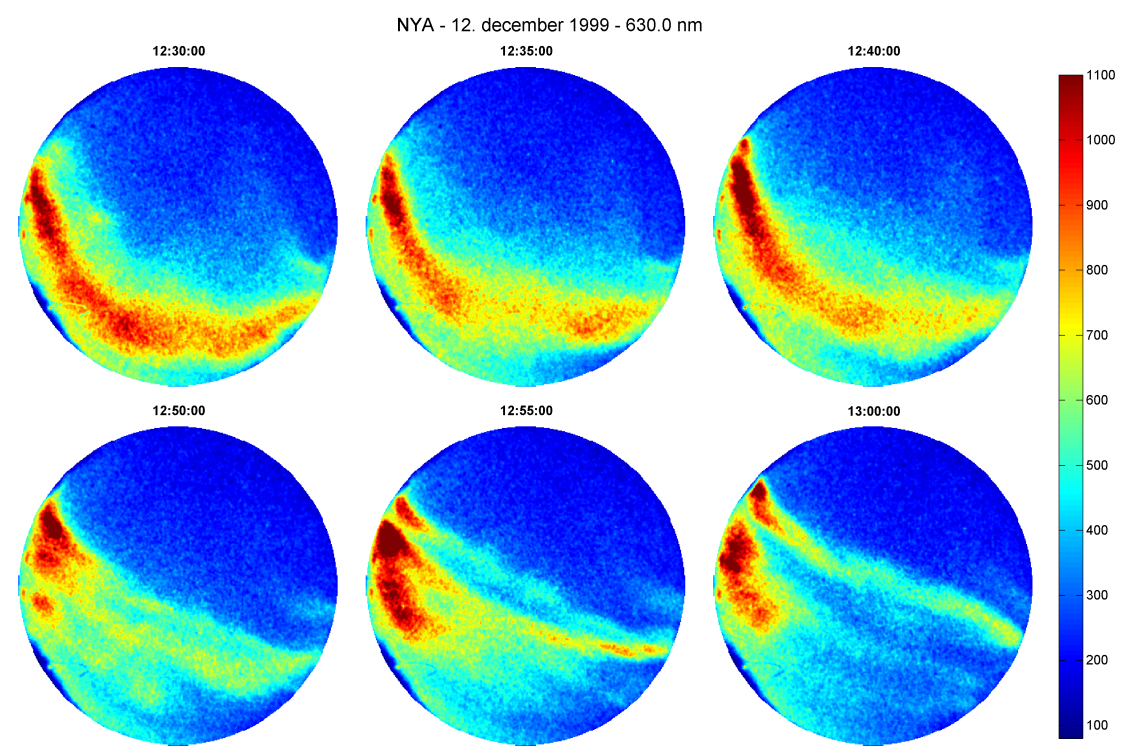

Fig. 7. ASC representation of the $630.0 \mathrm{~nm}$ emission for the interval 12:30-13:00 UT. Same format as in Fig. 5.

Figure 7 shows ASC images at $630.0 \mathrm{~nm}$ for the times 12:30, 12:35, 12:40 UT (upper row) and 12:50, 12:55, and 13:00 UT (lower row). We note the following features: (i) weakening of arc in southeast (lower right part) during the interval 12:35-12:40 UT, (ii) appearance of double cusp in the western part of the field of view during the interval 12:50-13:00 UT (northernmost branch is referred to as cusp 2), and (iii) polar arc extending eastward (tailward) from the strong cusp 2 emission (see 13:00 UT image). The change of auroral configuration from the upper row (12:30-12:40 UT) to the bottom row (12:50-13:00 UT) in Fig. 7 represents the response to a change in IMF clock angle from 160 to $100^{\circ}$.

\subsection{SuperDARN plasma convection data}

Figure 8 shows plasma convection vectors and flow streamlines obtained from SuperDARN radars (http://superdarn. jhuapl.edu) in the northern hemisphere during the following intervals: (i) 11:10-11:12 UT/14:40 MLT (upper left), (ii) 11:20-11:22 UT/14:50 MLT (upper right), (iii) 12:40-12:42 UT/16:10 MLT (lower left), and (iv) 12:5012:52 UT/16:20 MLT (lower right). The approximate FOV of the ASC in Ny Ålesund is marked by white circle in each panel. The radar data (ion drift vectors) are supplemented by a theoretical model of the electrostatic potential to obtain maps of plasma convection streamlines. SuperDARN (Greenwald et al., 1995) provides line-of-sight velocity measurements of the high-latitude ionosphere. These measurements are combined using the "Map Potential" fitting technique (Ruohoniemi and Baker, 1998) to produce maps of large-scale ionospheric convection.

The following features are important for this study: (i) The presence of strong westward flow (red arrows) in the merging cell (flow channels FC 1 and FC 2 in Fig. 2) at times 11:10, 11:20, and 12:40 UT. (ii) Strongly attenuated westward convection in the duskside merging cell at 12:50 UT compared to that at 11:10 UT. (We note that this inference is based on a spatial SuperDARN plot showing limited data coverage). (iii) Lobe cell convection (flow channel FC 4 in Fig. 2) is present at 12:50 UT and possibly at 11:20 UT. (iv) Strong flow shears are evident in the convection cell located slightly north of Ny Ålesund at 11:20 UT and well to the north of Ny Ålesund at 12:50 UT. The locations of these flow shears are consistent with the the presence of polar arcs in the optical data. As we shall see below, the activation of the lobe cell during the interval 12:30-13:05 UT (FC 4) gave rise to corresponding positive $\mathrm{H}$-component deflection recorded by high-latitude magnetometers on the Greenland east coast.

From the convection data in Fig. 8 we also notice the presence of flow channel FC 3 in the prenoon sector, located on the downstream side of the cusp/convection throat, at 11:10 and 11:20 UT (upper panel in Fig. 8).

\subsection{Ground magnetic observations}

Figure 9 shows magnetometer data from high latitudes on the Greenland eastcoast during the interval 09:00-14:00 UT (see http://www.dmi.dk/projects/chain/). The Greenland east chain is located $\sim 2 \mathrm{~h}$ to the west of the optical site on Svalbard. Local noon (12:00 MLT) at the station is at $\sim 10: 30 \mathrm{UT}$. We note the following features: (i) negative deflection during 10:30-11:00 UT, (ii) negative bay disappearing from 11:10 UT onwards, and (iii) positive deflection during the interval 12:30-13:05 UT. Positive H deflection corresponds to an eastward-directed equivalent ionospheric Hall current and associated westward-directed plasma convection (see lower 

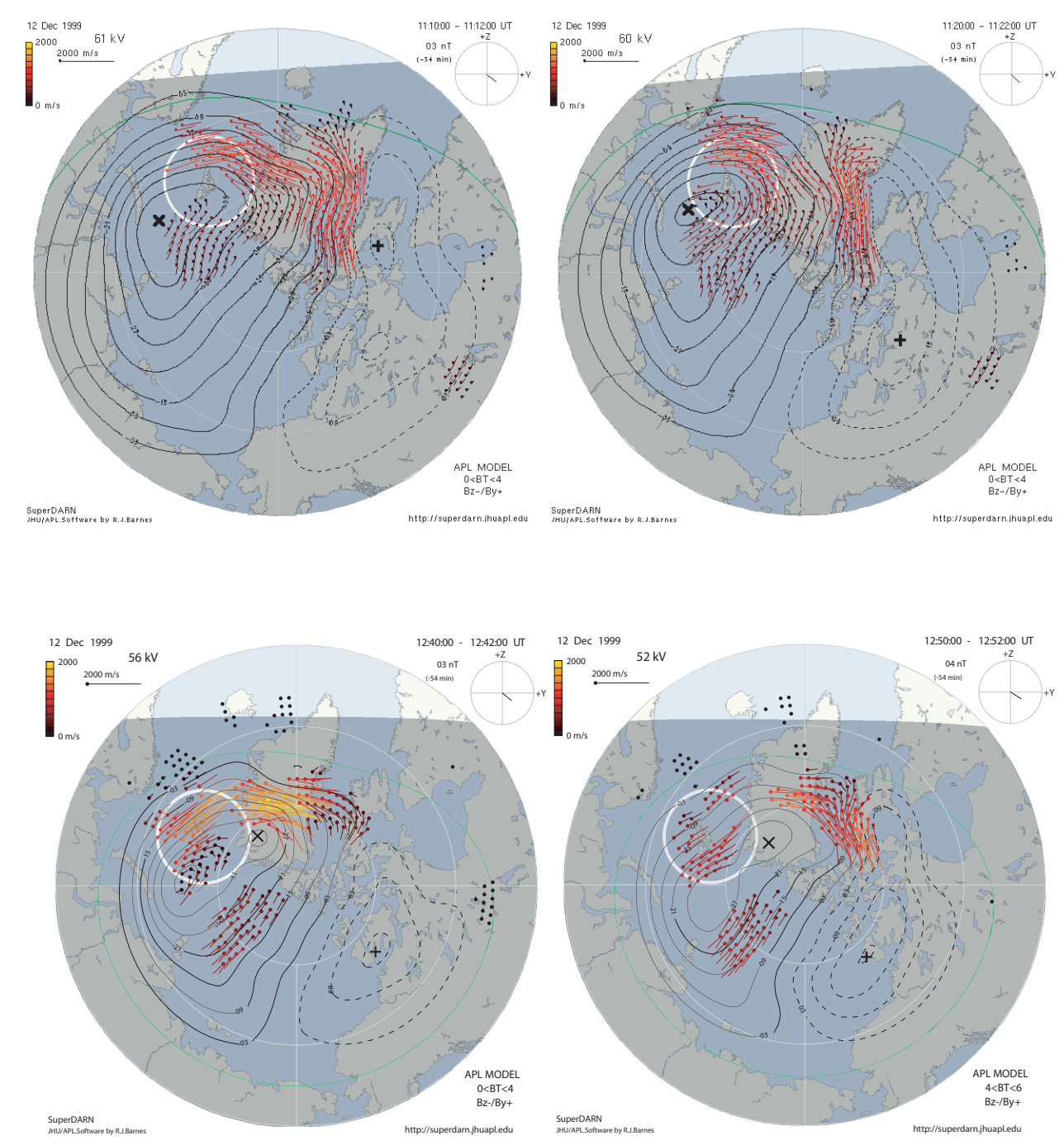

Fig. 8. Plasma convection data obtained from SuperDARN radars during the intervals 11:10-11:12 UT/14:40 MLT (upper left), 11:2011:22 UT/14:50 MLT (upper right), 12:40-12:42 UT/16:10 MLT (lower left), and 12:50-12:52 UT/16:20 MLT (lower right). White circle marks the approximate FOV of the ASC in Ny Ålesund.

right picture in Fig. 8). Features (ii) and (iii) correspond to the time of appearance of polar arcs in the auroral records from Ny Ålesund, Svalbard (Fig. 4). In the discussion section these features (polar arcs/positive H-deflection at high latitudes) will be related to activations of the lobe cell convection shown in Fig. 2.

\section{Discussion}

We have reported observations of the complex configuration of auroral forms and activities observed during southeast orientation of the IMF. The emphasis is on the system of cusppolar arcs in the postnoon sector. Before turning our attention to these observations we contrast them briefly with the prenoon observations shown in Fig. 3 in terms of the so- lar wind-magnetosphere-ionosphere interconnection topology illustrated in Fig. 10.

The high-latitude auroral brightening events seen in Fig. 3 during the interval 05:00-08:00 UT (08:3011:30 MLT/ $77-80^{\circ}$ MLAT) are interpreted in terms of solar wind-magnetosphere-ionosphere coupling on the oldopen magnetic field lines marked OO in Fig. 10. The associated system of FACs is marked C1-C2. For documentation of these currents we refer to Farrugia et al. (2003). The associated plasma convection channel (FC 3 in Fig. 2) is illustrated by the plasma convection data in our Fig. 8. We note that SuperDARN data also exist for the interval 05:00-08:00 UT, but the spatial coverage is not so good as later on this day. Convection data for 07:30 UT are shown in a recent paper where we discuss the PMAFs/prenoon versus PMAFs/postnoon in more detail (Sandholt and Farrugia, 2006b). 
The lower-latitude auroral brightening events observed during the interval 06:20-08:10 UT $(\sim 09: 50-$ 11:40 MLT/ $\left.\sim 73-75^{\circ} \mathrm{MLAT}\right)$ is attributed to a sequence of plasma injections on the newly open (NO) field lines (FTEs) shown on the prenoon (left) side in Fig. 10. The sequence of brightening events observed in the interval 08:30-10:40 UT is attributed to newly open field lines in the postnoon sector (marked $t_{0}$ in Fig. 10). Each of these brightenings are followed by PMAFs.

One important aspect of the present observations of postnoon activity from the ground is that we are able to supplement the precipitation pattern inferred from large statistical studies of satellite data (Newell et al., 2004) by new information on the small- and medium scale structure. The combination of ground observations of the aurora and plasma convection may allow us to distinguish between phenomena belonging to the merging- and lobe convection cells.

Our main objective is to document the detailed association that exists between aurora and plasma convection at high latitudes in the postnoon sector during intervals of steady IMF conditions with non-zero $B_{y}$ component (clock angle $=135^{\circ}$ ), and their responses to (i) the gradual southward and (ii) sharp eastward/northward IMF transitions recorded by Wind at 12:00-12:30 UT and 12:30 UT, respectively. The responses to these IMF variations help us to distinguish between the merging and lobe convection cells.

From the ground perspective we are able to distinguish between standard BPS arcs in the auroral oval in the southern part of the FOV and the oval-aligned polar arcs located further north. The following features of the observations are essential. (i) The first appearance of polar arcs along the Ny Ålesund meridian under steady south-east IMF conditions occurred at 11:10 UT (14:40 MLT), (ii) From this time onwards the aurora typically configures in two latitudinally separate branches. (iii) The auroral dynamics takes the form of a sequence of brightening events. (iv) Each of these brightening event consists of the successive activation of forms in the lower branch followed by forms in the higher-latitude branch. (v) The events in the high-latitude branch (polar arcs in 15:00-17:00 MLT/75-78 MLAT sector) are characterized by the following phase motions: (a) brightening and westward (noonward) expansion, followed by (b) fading and eastward retraction (see schematic illustration in Fig. 2). (vi) The sharp northward/eastward transition of the IMF at 12:30 UT elicited a fading of the low-latitude branch of the aurora and the activation of polar arcs at higher latitudes and the lobe convection cell during the interval 12:30-13:05 UT. (vii) The system of auroral forms which we refer to as cusp 2 - polar arcs (Fig. 2) is documented by ASC observations during the interval 12:50-13:05 UT (Fig. 7). (viii) The association between polar arcs and lobe cell convection is indicated by the convection data reported in Fig. 8 and the magnetograms shown in Fig. 9.

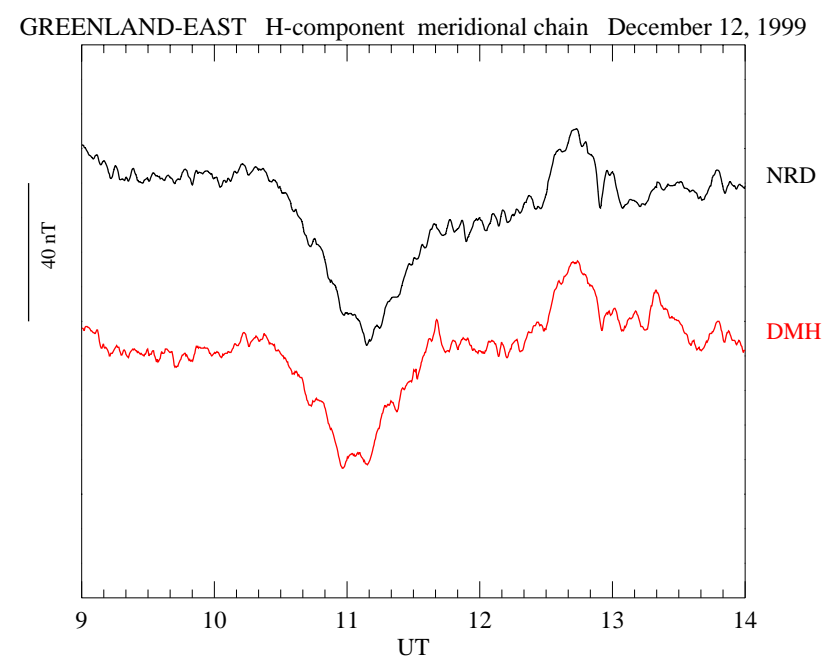

Fig. 9. Greenland east chain data for the interval 09:00-14:00 UT. Black and red traces show the H-component magnetic deflection recorded at stations Nord (NRD; $81^{\circ}$ MLAT) and Danmarkshavn (DMH; $\left.77^{\circ} \mathrm{MLAT}\right)$, respectively.

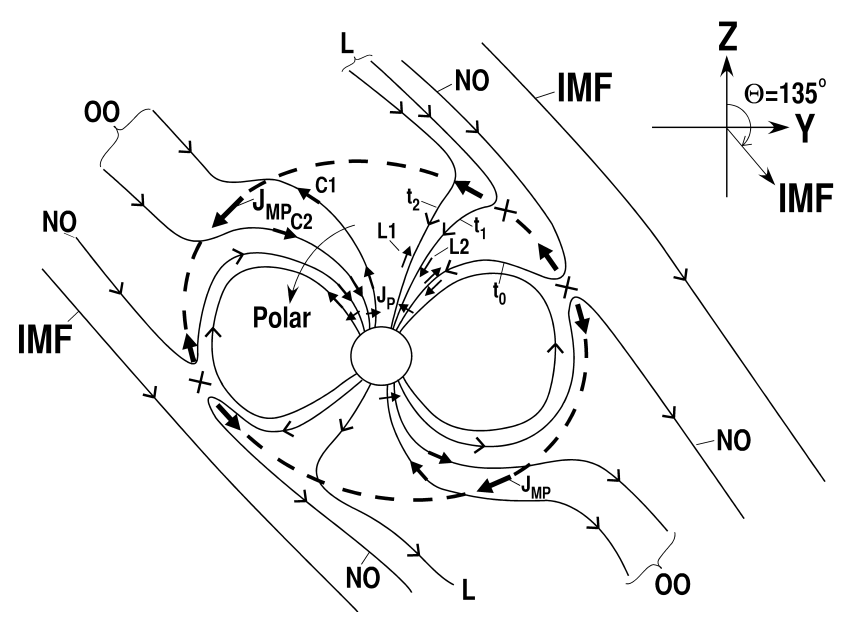

Fig. 10. Schematic view of the solar wind-magnetosphereionosphere interconnection topology for an IMF pointing southeast. The view is from the Sun. Merging and lobe reconnection lines (X) located in different planes on the postnoon/dusk side and the magnetic tension force on newly open field lines are indicated on the dawn and dusk sides. Newly open (NO), old open (OO), and open lobe $(\mathrm{L})$ field lines are marked. FACs linked to auroral forms in the pre- and postnoon sectors are indicated for the northern hemisphere. FACs flowing along old open field lines linked to the highlatitude boundary layer/magnetopause on the dawn (dusk) side in the northern (southern) hemisphere are marked C1-C2. The ionospheric closure via the Pedersen current there is marked $\boldsymbol{J}_{\boldsymbol{P}}$. Newly reconnected and recently reconnected lobe field lines are marked $t_{1}$ and $t_{2}$, respectively. FACs along these field lines are labelled L1 and L2. The track of spacecraft Polar on 3 December 1997 (see Farrugia et al., 2003) is indicated. Insert in upper right corner shows the IMF direction $\left(\theta=135^{\circ}\right)$ in GSM Y-Z coordiates. 
These observations will be discussed in relation to the schematic illustration of the solar wind/IMF-magnetosphereionosphere interconnection topology shown in Fig. 10. We note that this schematic is consistent with a recent MHD simulation study of the interconnection topology for the case of nonzero IMF $B_{y}$ component (Park et al., 2006). In the Park et al. (2006) study the indicated regions of magnetic reconnection on the pre- and postnoon sides appears as regions of low magnetic field intensity where the draped magnetosheath field is antiparallel to the geomagnetic field.

The FAC configuration shown on the dawn side is taken from ground-satellite conjunction studies by Sandholt and Newell (1992) and Farrugia et al. (2003). In the figure we distinguish between newly open (NO) and old open (OO) magnetic field lines. A lesson from the aurora (PMAFs) is that the reconnection process appears in the form of a sequence of pulses. Furthermore, the momentum transfer along the old open flux tubes via the FACs marked C1-C2 in Fig. 10 gives rise to a plasma convection channel at the boundary of the dawn-side polar cap that contributes significantly to the dawn-dusk asymmetry of plasma convection in the polar cap (marked FC 3 in Fig. 2).

A central feature in the interpretation of the dusk side observations is the distinction between reconnection X-lines located at sub-cusp and those located at latitudes of the magnetospheric lobe, as marked in Fig. 10. The following features are essential: (i) X-line at subcusp latitudes (in the region of near-antiparallel fields, as suggested by Crooker (1979) and Luhmann et al. (1984)) giving rise to a sequence of auroral brightening events centered in the 13:00-14:30 MLT sector (see Fig. 4). (ii) X-line at higher latitudes in the lobe giving rise to (a) the FAC system marked L1-L2, (b) the cusp 2 aurora, (c) a channel of enhanced sunward convection, and (d) polar arcs in the 15:00-17:00 MLT sector in our case (Fig. 4). (iii) The evolution of the reconnection process at the magnetopause involving sub-cusp and lobe events may be inferred from the aurora (see below). (iv) Channel of enhanced noonward (sunward) convection (marked FC 4 in Fig. 2) observed during the interval 12:30-13:05 UT and possibly during 11:20-11:30 UT (see magnetograms and SuperDARN data), giving rise to local flow shears and FACs. The brightening of the polar arcs is related to this.

The association between flow shear at the ionospheric level and polar arcs is well documented in theory and observations (Reiff et al., 1978; Burch et al., 1979; Eriksson et al., 2005). The phenomenon of enhanced sunward convection (our flow channel FC 4) and the associated FACs and polar arcs have been documented for northward IMF conditions by Eriksson et al. (2005). Here we report the similar phenomenon for a different IMF orientation characterized by clock angles within $\sim 100-135^{\circ}$. The presence of polar arcs and the lobe cell for southward IMF and $\left|B_{y} / B_{z}\right|>1$ conditions is in line with the MHD simulation studies of Crooker et al. (1998). The present study indicates that the ovalaligned polar arcs disappear (or retracts eastward, beyond our
FOV) only when the clock angle increases above $150^{\circ}$, as observed in the interval 12:00-12:30 UT in our case. Such behavior is in line with the idea of using the "anti-epsilon" function as a parameter for solar wind-magnetosphere coupling at high magnetopause latitudes (Kullen et al., 2002). "Anti-epsilon" approaches zero only for very high IMF clock angles.

From the present auroral observations we may infer interesting aspects of the evolution of the reconnection process on the magnetopause, as has been indicated in Fig. 10. In previous studies it has been suggested that the reconnection process appears in the form of a series of "reconnection waves" rolling over the magnetopause starting at the subsolar region and progressing tailward (Milan et al., 2000). In the present case the observation of the successive activations of auroral forms from lower to higher latitudes in the postnoon sector (Fig. 4) may be interpreted in terms of the successive activation of reconnection pulses at sub-cusp latitudes and in the lobe. This type of progression of the "reconnection wave" is indicated in Fig. 10 by the labelling of field lines with time markers $t_{0}, t_{1}$, and $t_{2}$. While $t_{0}$ marks the reconnection pulse at sub-cusp latitudes, labels $t_{1}$, and $t_{2}$ mark the evolution of field lines following a pulse of lobe reconnection. Thus, $t_{1}$ and $t_{2}$ represent different times that have elapsed since lobe reconnection. For clarity, we note that the X-line at lobe latitudes in Fig. 10 lies tailward of (one dimension is missing) the X-line at sub-cusp latitudes.

The FACs labelled L1-L2 in Fig. 10 is closed in the ionosphere by a Pedersen current. The associated poleward directed E-field gives rise to a channel of sunward convection (called FC 4 in Fig. 2). The L1-L2 FAC system is the FACs on open lobe field lines, poleward of the R1-R2 FACs, that has been documented by FAST data in Eriksson et al. (2002). Thus, in our view, the manifestation of a pulse of lobe reconnection in the magnetosphere-ionosphere system proceeds as follows: (i) activation of the L1-L2 currents, (ii) activations of the cusp 2 aurora and convection channel FC 4, (iii) enhanced flow shear (converging E-field) at the poleward boundary of FC 4, (iv) brightening/westward expansion of polar arcs (accelerated electrons in converging Efield regime; (see Reiff et al., 1978; Kullen et al., 2002) in the region of the outward-directed FAC marked L2, and (v) fading/retraction of the same polar arcs when lobe reconnection is switched off.

Finally we note that the most equatorward FAC pair on the dusk (right) side in Fig. 10 is closed in the ionosphere by a poleward directed Pedersen current. The upward-directed current component is closely associated with PMAFs (Lockwood et al., 1989) as observed in the interval 09:0011:00 UT in the present case (Figs. 3 and 4). 


\section{Summary and conclusions}

This paper addresses the question of spatial-temporal structure of the dayside magnetosphere-ionosphere system under southeast IMF conditions as inferred from the aurora. The aurora is a key parameter for understanding the finestructure of the inter-related system of particle precipitation, field-aligned currents, and plasma convection in the dayside magnetosphere. The dayside morphology under southeastand southwest directed IMF consists of the following essential elements (see Fig. 3):

(i) PMAFs/prenoon, (ii) the "midday gap aurora", (iii) PMAFs/postnoon, (iv) polar arcs, (v) the cusp 2 aurora in the postnoon sector, and (vi) the duskside BPS arc.

A characteristic IMF $B_{y}$-related precipitation asymmetry in PMAFs/prenoon versus PMAFs/postnoon has been documented in a recent paper (Sandholt and Farrugia, 2006b).

In the present paper we focus on the morphology in the 12:00-17:00 MLT sector during the prevailing positive $B_{y}$ conditions on 12 December 1999. Both spatial and temporal structures were observed. The spatial structure consists of the following elements, observed when the IMF clock angle is within $\sim 90-150^{\circ}$ :

(i) 12:00-15:00 MLT sector: a sequence of brightening events and associated noonward- and poleward moving forms (PMAFs/postnoon),

(ii) 15:00-17:00 MLT sector: latitudinally bifurcated aurora with brightening events progressing from the southern form (BPS arc) to the northernmost branch (polar arc).

The temporal structure consists of the following:

(i) disappearance of the northernmost branch (polar arcs) and intensification of the southernmost branch in response to a gradually increasing IMF clock angle (approaching $160^{\circ}$ ) during the interval 12:00-12:30 UT (15:30-16:00 MLT),

(ii) re-activation of the northernmost branch (polar arcs and cusp 2) and weakening of the southernmost form during the interval 12:40-13:05 UT.

The polar arc brightening events appearing within $\sim 75$ 77 MLAT/15:00-17:00 MLT are characterized by a sequential evolution of 2-3 forms that may be separated in two phases: (i) brightening and noonward (westward) expansion and (ii) fading and eastward retraction.

SuperDARN data are applied in order to place the observed auroral phenomena in the context of plasma convection. The following results are obtained: (i) the phenomenon of PMAFs/postnoon appearing at the poleward boundary of a convection channel (at $\sim 72-73^{\circ}$ MLAT/13:00-15:00 MLT) in the merging cell, (ii) polar arcs (at $\sim 75-77^{\circ}$ MLAT/15:0017:00 MLT) appearing in the region of flow shear in a smaller convection cell embedded within the larger duskside merging cell.

The polar arcs and small, high-latitude convection cell are suppressed when the IMF clock angle increases above $\sim 150^{\circ}$, while the same phenomena are activated/strengthened in association with the abrupt change of IMF clock an- gle from $\sim 160$ to $100^{\circ}$. (On the latter point, i.e., polar arc activation in response to northward turning of the IMF, we also refer to Sandholt et al. (2002b)). The smaller convection cell within the merging cell may be identified as a lobe cell or a viscous cell (see Reiff and Burch (1985)). The observed response to IMF variability indicate that it is a lobe cell.

Acknowledgements. The Wind data are courtesy of R. P. Lepping and K. W. Ogilvie. We thank B. Lybekk and E. Trondsen for technical assistance during the auroral observation campaigns in $\mathrm{Ny}$ Ålesund, and with the presentation of the optical data. Magnetometer data from the Greenland east chain has been kindly provided by J. Watermann (see http://www.dmi.dk/projects/chain/). The auroral observation program on Svalbard is supported by the Norwegian Research Council, the Norwegian Polar Research Institute and AFOSR Task 2311AS. This work is supported in part by NASA Living with a Star grant NAG5-12189, NASA Wind/SWE and MFI grant NNG05GC75G, and by NASA grant NNG05GG25G.

Topical Editor I. A. Daglis thanks L. Blomberg and another referee for their help in evaluating this paper.

\section{References}

Burch, J. L., Fields, S. A., and Heelis, R. A.: Polar cap electron acceleration region, J. Geophys. Res., 84, 5863-5874, 1979.

Crooker, N. U.: Dayside merging and cusp geometry, J. Geophys. Res., 84, 951-959, 1979.

Crooker, N. U., Lyon, J. G., and Fedder, J. A.: MHD model merging with IMF $B_{y}$ : Lobe cells, sunward polar cap convection, and overdraped lobes, J. Geophys. Res., 103, 9143-9151, 1998.

Dandekar, B. S. and Pike, C. P.: The midday discrete auroral gap, J. Geophys. Res., 83, 4227-4236, 1978.

Eriksson, S., Bonnell, J. W., Blomberg, L. G., Ergun, R. E., Marklund, G. T., and Carlson, C. W.: Lobe cell convection and fieldaligned currents poleward of the Region 1 current system, J. Geophys. Res., 107(A8), 1185, doi:10.1029/2001JA005041, 2002.

Eriksson, S., Peria, W. J., Bonnell, J. W., Su, Y. J., Ergun, R. E. Tung, Y. K., Parks, G. K., and Carlson, C. W.: Lobe cell convection and polar cap precipitation, J. Geophys. Res., 108(A5), 1198, doi:10.1029/2002JA009725, 2003.

Eriksson, S., Baker, J. B. H., Petrinec, S. M., Wang, H., Rich, F. J., Kuznetsova, M., Dunlop, M. W., Reme, H., Greenwald, R. A., Frey, H. U., Luhr, H., Ergun, R. E., and Balogh, A.: On the generation of enhanced sunward convection and transpolar aurora in the high-latitude ionosphere by magnetic merging, J. Geophys Res., 110, A11218, doi:10.1029/2005JA011149, 2005.

Farrugia, C. J., Sandholt, P. E., Maynard, N. C., Torbert, R. B., and Ober, D. M.: Temporal variations in a four-sheet fieldaligned current system and associated aurorae as observed during a Polar-ground magnetic conjunction in the midmorning sector, J. Geophys. Res., 108(A6), 1230, doi:10.1029/2002JA009619, 2003.

Fasel, G.: Dayside poleward moving auroral forms: A statistical study, J. Geophys. Res., 100, 11 891-11 906, 1995.

Greenwald, R. A., Baker, K., Dudeney, J. R., Pinnock, M., Thomas, E. C., Villain, J. P., Cerisier, J.-C., Senior, C., Hanuise, C., Hunsucker, R. D., Sofko, G. J., Koehler, J., Nielsen, E., Pellinen, R., Walker, A. D. M., Sato, N., and Yamagishi, H.: 
DARN/SUPERDARN: A Global View of the Dynamics of HighLatitude Convection, Space Sci. Rev., 71, 761-796, 1995.

Kullen, A., Brittnacher, M., Cumnock, J. A., and Blomberg, L. G., Solar wind dependence of the occurrence and motion of polar auroral arcs: A statistical study, J. Geophys. Res., 107(A11), 1362, doi:10.1029/2002JA009245, 2002.

Lockwood, M., Sandholt, P. E., Cowley, S. W. H., and Oguti, T., Interplanetary magnetic field control of dayside auroral activity and the transfer of momentum across the dayside magnetopause, Planet. Space Sci., 37, 1347-1365, 1989.

Luhmann, J. G., Walker, R. J., Russell, C. T., Crooker, N. U., Spreiter, J. R., and Stahara, S. S.: Patterns of potential magnetic field merging sites on the dayside magnetopause, J. Geophys. Res., 89, 1739-1744, 1984.

Maynard, N. C., Burke, W. J., Sandholt, P. E., Moen, J., Ober, D. M., Lester, M., Weimer, D. R., and Egeland, A., Observations of simultaneous effects of merging in both hemispheres, J. Geophys. Res., 106, 24 551-24 578, 2001.

Maynard, N. C., Ober, D. M., Burke, W. J., Scudder, J. D., Lester, M., Dunlop, M., Wild, J. A., Grocott, A., Farrugia, C. J., Lund, E. J., Russell, C. T., Weimer, D. R., Siebert, K. D., Balogh, A., Andre, M., and Reme, H.: Polar, Cluster and SuperDARN evidence for high-latitude merging during southward IMF: temporal/spatial evolution, Ann. Geophys., 21, 2233-2258, 2003.

Milan, S., Lester, M., Cowley, S. W. H., and Brittnacher, M.: Convection and auroral response to a southward turning of the IMF: Polar UVI, CUTLASS and IMAGE signatures of transient flux transfer at the magnetopause, J. Geophys. Res., 105, 15741$15756,2000$.

Moore, T. E., Fok, M.-C., and Chandler, M. O.: The dayside reconnection X line, J. Geophys. Res., 107(A10), 1332, doi:10.1029/2002JA009381, 2002.

Newell, P. T. and Meng, C. I.: The cusp and the cleft/boundary layer: Low-altitude identification and statistical local time variation, J. Geophys. Res., 93, 14 549-14 556, 1988.

Newell, P. T., Ruohoniemi, J. M., and Meng, C. I.: Maps of precipitation by source region, binned by IMF, with inertial convection streamlines, J. Geophys. Res., 109, A10206, doi:10.1029/2004JA10499, 2004.

Park, K. S., Ogino, T., and Walker, R. J.: On the importance of antiparallel reconnection when the dipole tilt and IMF $B_{y}$ are nonzero, J. Geophys. Res., 111, A05202, doi:10.1029/2004JA010972, 2006.

Reiff, P. H. and Burch, J. L.: IMF $\mathrm{B}_{\mathrm{y}}$-dependent dayside plasma flow and Birkeland currents in the dayside magnetosphere, 2, A global model for northward and southward IMF, J. Geophys. Res., 90, 1595-1609, 1985.

Reiff, P. H., Burch, J. L., and Heelis, R. A.: Dayside auroral arcs and convection, Geophys. Res. Lett., 5, 391-394, 1978.

Ruohoniemi, J. M. and Baker, K. B.: Large-scale imaging of highlatitude convection with Super Dual Auroral Radar Network HF radar observations, J. Geophys. Res., 103, 20 797-20 811, 1998.
Sandholt, P. E. and Farrugia, C. J.: Multipoint observations of substorm intensifications: The high-latitude aurora and electron injections in the inner equatorial plasma sheet, Geophys. Res. Lett., 28, 483-486, 2001.

Sandholt, P. E. and Farrugia, C. J.: Does the aurora provide evidence for the occurrence of antiparallel magnetopause reconnection?, J. Geophys. Res., 108(A12), 1466, doi:10.1029/2003JA010066, 2003.

Sandholt, P. E. and Farrugia, C. J.: Spatiotemporal structure of the reconnecting magnetosphere under $B_{y}$-dominated interplanetary magnetic cloud conditions, J. Geophys. Res., 111, doi:10.1029/2005JA011514, 2006a.

Sandholt, P. E. and Farrugia, C. J.: The role of poleward moving auroral forms in dawn-dusk asymmetry of auroral precipitation induced by IMF $B_{y}$, J. Geophys. Res., in press, 2006 b.

Sandholt, P. E. and Newell, P. T.: Ground and satellite observations of an auroral event at the cusp/cleft equatorward boundary, J. Geophys. Res., 97, 8685-8691, 1992.

Sandholt, P. E., Lockwood, M., Oguti, T., Cowley, S. W. H., Freeman, K. S. C., Lybekk, B., Egeland, A., and Willis, D. M.: Midday auroral breakup events and related energy and momentum transfer from the magnetosheath, J. Geophys. Res., 95, 10391060, 1990.

Sandholt, P. E., Farrugia, C. J., Moen, J., Noraberg, Ø., Lybekk, B., Sten, T., and Hansen, T.: A classification of dayside auroral forms and activities as a function of IMF orientation, J. Geophys. Res., 103, 23 325-23 346, 1998.

Sandholt, P. E., Farrugia, C. J., Cowley, S. W. H., and Lester, M.: Dayside auroral bifurcation sequence during $B_{y}$-dominated interplanetary magnetic field: Relationship with merging and lobe convection cells, J. Geophys. Res., 106, 15 429-15 444, 2001.

Sandholt, P. E., Farrugia, C. J., Lester, M., Cowley, S. W. H., Milan, S., Denig, W. F., Lybekk, B., Trondsen, E., and Vorobjev, V.: Multistage substorm expansion: Auroral dynamics in relation to plasma sheet particle injection, precipitation, and plasma convection, J. Geophys. Res., 107(A11), 1342, doi:10.1029/2001JA900116, 2002a.

Sandholt, P. E., Farrugia, C. J., Moen, J., and Denig, W. F.: The cusp in rapid transition, J. Geophys. Res., 107(A12), 1427, doi:10.1029/2001JA009214, 2002b.

Sandholt, P. E., J., M., Farrugia, C. J., Cowley, S. W. H., Lester, M., Milan, S. E., Valladares, C., Denig, W. F., and Eriksson, S.: Multi-site observations of the association between aurora and plasma convection in the cusp/polar cap during a south-eastward ( $B_{y} \simeq\left|B_{z}\right|$ ) IMF orientation, Ann. Geophys., 21, 539-558, 2003.

Sandholt, P. E., Farrugia, C. J., and Denig, W. F.: Detailed dayside auroral morphology as a function of local time for southeast IMF orientation: implications for solar wind - magnetosphere coupling, Ann. Geophys., 22, 3537-3560, 2004.

Southwood, D. J.: The ionospheric signature of flux transfer events, J. Geophys. Res., 92, 3207-3213, 1987.

Weimer, D. R.: Models of high-latitude electric potentials derived with a least error fit of spherical harmonic coefficients, J. Geophys. Res., 100, 19595-19608, 1995. 